\title{
¿La religión, competente en materia de verdades y valores?
}

Recibido: 4 de mayo 2018 Revisado: 25 de mayo 2018 Aprobado: 19 de julio 2018

José Amando Robles

Español nacionalizado costarricense, licenciado en filosofía y teología, doctor en sociología y especialista en sociología de la religión. Desde hace años interesado en la axiología y

espiritualidad en la sociedad de conocimiento. Fue profesor en la Escuela

Ecuménica de Ciencias de la Religión de la Universidad Nacional de Heredia, Costa

Rica, y actualmente es coordinador del Programa Maestro Eckhart del Centro Dominico de Investigación (CEDI), Heredia, Costa Rica.

Entre sus publicaciones destacan La religión. De la conquista a la modernidad

(1992), Religión y paradigmas (1995), Para una nueva espiritualidad (cosmoteándrica). Aportes en Raimon Panikkar, 2006, ¿Verdad o símbolo? Naturaleza del lenguaje religioso (2007), Repensar la religión. De la creencia al conocimiento (2001), La religión en la sociedad de conocimiento (2010). Correo electrónico: jarobles@cedi.cr
Resumen: Como sucedió en las elecciones generales pasadas en Costa Rica, por toda América Latina están surgiendo partidos cristianos, especialmente neopentecostales, presentándose como defensores $\mathrm{y}$, por tanto poseedores, de verdades y valores que ellos ven en peligro: concepción de la vida, sexualidad, pareja humana, entre otros. $Y$ es frecuente, hasta en medios laicos, reconocerles cierta competencia. A este respecto hay que hacerse ya académicamente la pregunta, y el presente trabajo la hace: ¿en verdad las religiones tienen verdades específicas al respecto? Y la respuesta es negativa. En el pasado bajo una epistemología mítica se creían competentes y lo eran. Hoy, bajo una epistemología crítica, no lo son más. Sus verdades y valores son los de las antropologías, éticas y filosofías que asumen, con frecuencia ya caducadas, sin vigencia epistemológica. Definitivamente, la pretensión de las iglesias tiene que ser sometida a debate.

Palabras clave: Religión; neopentecostales; epistemología mítica; elecciones; América Latina

\section{Is Religion, Competent in Matters of Truths and Values?}

Abstract: As happened in the last general elections in Costa Rica, Christian parties are emerging throughout Latin America, especially neo-Pentecostals, presenting themselves as defenders and, therefore possessors, of truths and values that they see in danger: conception of life, sexuality, human couple, etc. And it is common, even in secular media, to recognize them some competence. In this regard, the question has to be asked academically, and the present work does: do religions really have specific truths about it? And the answer is negative. In the past, under a mythical epistemology, they believed they were competent and they were. Today, under a critical epistemology, they are no longer so. Its truths and values are those of the anthropologies they assume: ethics and philosophies often already expired, without epistemological validity. Definitely, the pretension of the churches has to be submitted to debate.

Key words: Religion; neo-Pentecostalism; mythical epistemology; elections; Latin America 
1. Aunque todavía en estas elecciones no faltó un connotado líder religioso, evangélico, atribuyendo lo moderado del daño de un determinado terremoto altamente potente en el país (el terremoto de Nicoya de 2012), a la "orden religiosa" de mantenerse bien alineadas entre sí y no hacer daño que él in situ días antes había dado a las placas tectónicas respectivas. Es decir, aún quedan residuos en personas de una visión mágico-religiosa de fenómenos meramente telúricos y cósmicos.
La presencia protagónica, y en ciertos sectores sociales determinante, que ha tenido la religión en nuestras elecciones presidenciales recién pasadas sobre todo con la irrupción exitosa de un partido evangélico fundamentalista - ha generado mucha discusión acerca de religión y de política electoral, tanto en términos coyunturales como teóricos. Esto se ha hecho de manera muy sensible, dado que electores creyentes e instituciones religiosas no siempre respetaron lo que nuestra Constitución Política prescribe en su número 28: «No se podrá, sin embargo, hacer en forma alguna propaganda política por clérigos y seglares invocando motivos de religión o valiéndose, como medio, de creencias religiosas». Sin embargo, como es habitual en situaciones como esta, ni se han abordado todos los puntos, algo de todo imposible, ni los más importantes, tarea muy necesaria y deseable, por ejemplo: la competencia o no competencia de la religión en dominios de la sexualidad, educación y familia.

Como es normal, los puntos abordados han sido los políticamente más inmediatos y urgentes. Por el contrario, cuando hablamos de asuntos esenciales, nos estamos refiriendo a los de naturaleza antropológica, epistemológica y axiológica: a verdades y a valores que se vinculan con la concepción del ser humano, su origen y destino, naturaleza transcendente de la vida humana, concepción de la sexualidad humana; a verdades y a valores éticos, personales y sociales, responsabilidad humana para con el planeta y el cosmos, sentido y fin de la historia humana...

Esos supuestos y concepciones son determinantes porque de ellos derivan todos los demás, como han sido los que han estado en discusión en esta coyuntura electoral y lo seguirán estando todavía por mucho tiempo. Pues bien, aun reconociendo su importancia social y política, entrado ya el siglo XXI y dada la naturaleza epistemológica de la sociedad y cultura que estamos construyendo, esta es la pregunta epistemológica que debemos hacernos y responder: ¿de verdad la religión -y por tanto las iglesias- tiene competencia en este tipo de verdades y de valores, de manera que podemos seguir hablando de la relación religión y política electoral o política en general reconociéndole a la religión tal competencia? Este es el tema que abordaremos en el presente trabajo, elemento clave por la razón señalada.

Primero, haremos eco de esa competencia habitualmente reconocida a la religión, por la amplitud y actualidad de las que todavía goza, sobre todo en el dominio de lo antropológico, social y político, ya no así en el dominio de lo físico y cósmico ${ }^{1}$, y ello incluso por parte del pensamiento laico.

En un segundo momento, desmentiremos dicha competencia al exponer la naturaleza no-naturaleza que caracteriza al ser humano, enfatizando cómo este no nace con verdades ni valores, mucho menos religiosos, sino que él mismo los tiene que construir. 
En un tercer momento, daremos cuenta de la dimensión absoluta constitutiva del ser humano, dimensión que es invención de la biología, por tanto, no religiosa, aunque en ella pareciera fundarse la religión, que tampoco es portadora de valores ni de verdades sobre la vida humana, ser humano, sexualidad y familia, no digamos ya sobre economía, política y organización social.

En un cuarto paso, mostraremos cómo y cuándo las religiones se constituyeron como portadoras de verdades y de valores, en unas condiciones de vida bien concretas, preindustriales y bajo una epistemología mítica, configurándose las religiones como proyectos axiológicos colectivos. Para terminar planteando, en un quinto y último paso, cómo, en la actualidad al transformarse las condiciones de vida que los originaron y les permitieron su desarrollo; su epistemología; el dominio de lo humano, de lo social y de lo político, las religiones pierden el reconocimiento de competencia en verdades y valores que habían adquirido. A partir de esta pérdida, reaccionan, por todos los medios, a su alcance, reconocimiento y competencia por los que luchan y se reivindican.

A partir del segundo momento en nuestro planteamiento y reflexión, nos estaremos apoyando en la propuesta/el enfoque antropológica y epistemológica axiológica hecha por Marià Corbí, especialmente, en sus cinco obras que llevan por subtítulo "Principios de Epistemología Axiológica", en las cuales aborda estos temas de manera particular. No conocemos otro autor que lo haya hecho con tanta especificidad, rigor y pertinencia.

En virtud de lo anterior, es obligado apoyarnos en sus aportes, además de la importancia de publicarlos al ser poco conocidos en nuestro medio. Concretamente, nos apoyaremos en su concepción antropológica del ser humano como animal viviente hablante, en el doble acceso que el habla nos ofrece de la realidad. Esto genera la constitución del ser humano por dos dimensiones: una con relación a su vida y otra absoluta, es decir, sin referencia a la vida, en la religión configurada como proyecto axiológico colectivo en las condiciones de vida preindustriales, y en la espiritualidad, ya no en la religión de creencias o verdades, como cualidad humana profunda, dimensión de realización plena, sin contenidos ni forma, por tanto, sin verdades ni valores.

\section{Una competencia supuesta de verdades y valores}

La concepción de la religión como fuente de verdades y de valores viene de lejos, desde que fue concebida como revelación, no solamente sobre Dios, sino - no podría ser menos - sobre el ser humano, el mundo, el universo y la historia, en función de su realización plena (salvífica); fenómeno típico de las sociedades agrarias y de las religiones monoteístas. Desde entonces, la supuesta revelación ya comprende objetivamente dos órdenes de verdades y valores: divinas y humanas. Por un lado, las primeras en cuanto reveladas por Dios. Por otro lado, las segundas porque están al alcance del ser huma- 
2. Tal es la concepción del matrimonio debidamente celebrado y "consumado" que tiene un sector tradicional de la jerarquía católica (cardenales, obispos y teólogos) frente al papa Francisco. Tan inmutable que, según ellos, ni Jesucristo mismo podría anular su indisolubilidad $\mathrm{ni}$, en consecuencia, permitir que los divorciados vueltos a casar puedan recibir la comunión sacramental, menos el papa.

3. Blog Suma teológica, http://hjg.com.ar/sumat/b/c91.ht $\mathrm{ml}$ no. No obstante, unas y otras se han considerado divinas al ser reveladas por Dios como verdades y valores, esto es, dotadas de la más grande autoridad que el ser humano puede concebir o imaginar: Dios. Un ejemplo de ello en el judeocristianismo lo constituyen los famosos diez mandamientos de la ley (Ex 20, 1-17; Dt 5, 6-22), para judíos y cristianos, mandamientos revelados por Dios, pero a la vez humanamente justificables y razonables.

Esa doble naturaleza de verdades y valores, muy frecuente en la Biblia, será muy importante a lo largo de la historia del cristianismo, como todavía lo es hoy, porque actuará como un blindaje divino, el más radical que el ser humano les ha podido inventar a verdades y a valores antropológicos y cosmológicos, en el mejor de los casos meramente humanos y naturales, y como tales, culturales e históricos, propios de ciertas formas de vida. Piénsese en los fundamentalismos cristianos actuales, católicos o protestantes, para los que su concepción sobre la vida humana, sexualidad, matrimonio y familia es una concepción revelada, divina, inmutable ${ }^{2}$.

La tematización de esa doble naturaleza; divina y humana, en una serie amplia de verdades reveladas, obviamente, vino después. En el caso del cristianismo, comienza en el encuentro con el pensamiento griego, con el "logos", en el proceso conocido como helenización del cristianismo, de su inculturación en el mundo griego. Ello ocurre de la mano de lo que para los cristianos es un descubrimiento nuevo: el de la razón o "logos", que ven plenamente armonioso con su fe: que todo, naturaleza y ser humano, está hecho de acuerdo con una razón y con una ley; ley que el ser humano es capaz de descubrir con su razón y debe seguir para realizarse como tal.

Ese es el ser de las cosas, de la naturaleza, del ser humano, el cual se hace ética, principios y normas, primeros y fundamentales, que hay que seguir. Es la lex naturalis o moral natural inserta como ley en todo lo creado, pero en particular en el ser humano, y por ello, asumida por y en la revelación, ya que en el judeocristianismo, como posteriormente en el Islam, el Dios que salva es el mismo Dios que crea.

La creación existe en función de la salvación, pero a su vez el Dios de la salvación, con sus atributos y verdades, se refleja en la creación. En otras palabras, la creación es revelación y como tal conduce a la salvación. La creación no es mera creación, en cierto grado, es divina, participa de los mismos grandes principios y valores de la revelación y lleva al reconocimiento de estos. De ahí, la importancia de la recta razón, como llama Cicerón (106-43 a. C.) a la razón conocedora de esta dimensión ética inserta en todas las cosas y en el ser humano, razón que se identifica con la ley natural.

La tematización comenzó a darse entonces, pero la elaboración madura como doctrina fue obra de la primera escolástica, bajo el concepto de ley natural, todavía hoy utilizado en la Iglesia católica. Tomás de Aquino, considerado su arquitecto y constructor principal, la definirá: "la participación de la ley eterna en la creatura racional" ${ }^{3}$. Como doctrina, conoció aplicaciones modernas con ocasión del descubrimiento y conquista del Nuevo Mundo. En otras palabras, ante la novedad humana laica antropológica, social y política que 
supuso, para Europa, el descubrimiento de nuevos pueblos para ella, y que dio lugar a la formulación del "derecho de gentes" con Francisco de Vitoria. Y de nuevo, es actualizada y desarrollada por la Iglesia católica ante la novedad laica, con sus retos, que supone la modernidad con su autonomía de lo religioso.

El cristianismo que más ha desarrollado la doctrina es el católico, no así el protestante ${ }^{4}$, que, en su visión teológica más pesimista del ser humano y del mundo, menos la ha necesitado, pues ha absolutizado más el carácter sobrenatural de la revelación. Por una parte, al protestantismo le basta, para ratificar una verdad, enfatizar que esta ha sido revelada por Dios; no necesita enfatizar tanto la mediación de la naturaleza y del ser humano como fuente y criterio de verdad; es más fideísta. Por otra parte, al catolicismo le gusta más desarrollar naturaleza y ser humano como fuente y criterio de verdad, sobre todo, cuando aparecen situaciones laicas, como las hemos calificado, que, en principio, no estarían reveladas, y en su autonomía cultural y social, se resisten a enmarcarse en un cuadro religioso de revelación. Es más racionalista.

La ley natural como doctrina no es cristianamente ingenua, en el sentido de inocente, como tampoco es meramente revelada. Al reconocer, a través de ella, un valor salvífico a todo lo creado y a sí misma como ley natural y humana suprema, la fe cristiana acepta el valor "cristiano", en el sentido de revelador y de salvador; asimismo, a todo lo que identifica con esa ley: creación, vida humana, persona, sexualidad, familia, orden social y autoridad. De esta manera, se mueve en dos órdenes o campos: el de la fe cristiana, por no decir más bien la Iglesia, lo considera propiamente revelado; y el que supone natural y humano, en ambos órdenes es plenamente competente.

La Iglesia, fundada por Jesucristo, para cumplir la que cree que es su vocación y misión divinas: salvar a la humanidad, tiene por evidencia la custodia e interpretación de dicha revelación. Sin embargo, dado el vínculo tan estrecho entre los principios y valores, insertos en la naturaleza y en el ser humano y su salvación, tiene que ser, y así concluye ella, intérprete, competente y garante de la ley natural. De esta foma, explícitamente, se proclama en su doctrina sobre la ley natural, en particular, en su confesión católica ${ }^{5}$. De lo contrario, no ve cómo cumpliría con su vocación y misión.

Para hablar salvíficamente de Dios, el ser humano -ser personal, social y político- siente que debe conocer a Este, así como su naturaleza, cuya doctrina es quien la capacitó: Dios, para conocer lo divino y la esencia y naturaleza de lo humano. En su caso, este conocimiento no sería tanto producto de la razón humana (ya lo es) como de un desvelamiento y desarrollo de la revelación, en que la concepción correcta del ser humano, la naturaleza y el proyecto humano estarían incluidos. Es la razón humana. Según la Iglesia, cree actuando bajo la luz y guía de la revelación.

Dicha doctrina al respecto no es inocente ni ingenua, como tampoco lo han sido los tiempos en que más ha sido desarrollada, a saber: helenización del cristianismo; primera escolástica, sigo XIII; segunda escolástica, en el siglo

Aunque también ha sido abordada en el protestantismo, Cf. Manuel Morales, "Teología natural y protestantismo, una relación compleja", en

Tendencias 21. Tendencias de las Religiones,

https://www.tendencias21.net/T eologia-Natural-y-

Protestantismo-una-relacion-

compleja a6067.html.

Consultada el 25/03/18.

5. Blog Congregación para la doctrina y la fe,

http://www.vatican.va/roman_c uria/congregations/cfaith/cti

documents/rc_con_cfaith_doc 20090520_legge-naturale_sp.ht $\mathrm{ml}$ 
$\mathrm{XVI}$ con la Escuela de Salamanca ante la conquista de América; en el siglo XVIII-XIX con la llustración, ante la sociedad industrial moderna y laica; y en la actualidad, ante una sociedad que ejecuta una revolución científico-tecnológica, más radicalmente laica todavía.

Con esa doctrina, la Iglesia, sin renunciar a lo que cree que es su misión divina -todo lo contrario realizándola-, se ubica en condición de interlocutora importante, e incluso necesaria del pensamiento moderno laico y en la construcción de la sociedad. En principio, porque se puede presentar, aparentemente, en condiciones de igualdad con la laicidad que la reta, pues en el fondo, comparten los mismos retos y desafíos. En otras palabras, comprenden la modernidad en las aspiraciones de esta, y, gracias a la garantía que supone la revelación de la que es depositaria e intérprete, tiene la pretensión de conocer la modernidad mejor, incluso que a sí misma.

La doctrina de la ley natural le presenta grandes ventajas a la Iglesia, además de que ha ofrecido grandes aportes en diferentes momentos. Ella le permite considerarse y presentarse como experta en humanidad, como declaró el papa Pablo VI en su visita a las Naciones Unidas (octubre de 1965), y que al magisterio eclesiástico, a los pastores y a los teólogos les gusta repetir. Su interlocutor es todos los seres humanos, todas las sociedades, con todas sus culturas.

Lo que la Iglesia considera como ley natural: los principios y valores, de acuerdo con los cuales el ser humano está constituido y debe comportarse, son, según la misma doctrina, universales, cognoscibles de todos los seres humanos e incluso inmutables. La ley natural, en efecto, según su doctrina, es universal, inmutable y cognoscible por todos (Iglesia católica 1992). Si no es conocida, de manera fácil e inmediata, por todos los seres humanos es por el pecado, aspecto en el cual la Iglesia también es maestra.

Aun con esa limitación del pecado, la ley natural obliga, por lo tanto, a todos los seres humanos. De acuerdo con la definición de santo Tomás de Aquino, es participación de la ley eterna en la razón humana, cumpliendo la ley natural. En otras palabras, no debe haber conflicto entre razón y fe, realización del ser humano y revelación, sino que revelación y fe significan la plenitud del ser humano y son garantía de la realización humana de individuos y de pueblos. El cumplimiento de la ley natural lleva al Dios de la revelación judeocristiana, e incluso a Jesucristo, suprema revelación de Dios según la Iglesia, y mediador necesario para llegar a Él. En virtud de esta articulación, la ley natural y lo que es de su competencia, que es algo natural y humano, se vuelve religioso, más aún, se vuelve cristiano.

Así concebida y desarrollada la doctrina de la ley natural, se comprenderá por qué la Iglesia católica la está desarrollando tanto desde finales del siglo XIX con el papa León XIII hasta nuestros días, en plena modernidad laica, y es objeto de documentos fundamentales del magisterio eclesiástico, verbigracia: el Catecismo de la Iglesia Católica (1992); las Cartas Encíclicas Veritatis splendor (1993); y Fides et ratio (1998). No cabe duda que sus contribuciones doctrinales han sido y son claves, como lo muestran, entre otras, las en- 
cíclicas Pacem in terris (1963) de Juan XXIII y la Populorum progressio (1967) de Pablo VI.

A pesar de dichas ventajas, presenta flancos débiles que la hacen criticable, como las supuestas creencias de los que parte, pues no son nada científicos y hoy muy difíciles de mantener: un Dios creador del universo y del ser humano; y la concepción de Este, como dotado de cuerpo y espíritu, de animalidad y de racionalidad. Sin estos supuestos, la doctrina de la ley natural, tal como el magisterio eclesiástico y la teología institucional la presentan, sería inconcebible.

Además del método deductivo que la caracteriza y su universalismo abstracto, la Iglesia presenta, como universales e inmutables, verdades y valores, los cuales en el fondo son sociales y cultural e históricamente limitados; de hecho, correspondientes y funcionales a formas de vida ya pasadas. De ahí que la Iglesia misma sienta la necesidad de actualizar la doctrina de la ley natural, esencial y fundamental para ella, y la defiende, incluso de críticas muy significativas hechas desde su interior ${ }^{6}$. Tal fue el objetivo de la encíclica Veritatis splendor ${ }^{7}$, la cual reivindica a su interior el valor objetivo de sus normas morales (la primera de esta naturaleza en la historia del magisterio de la Iglesia).

Para el cristianismo que representa la Iglesia católica, la doctrina de la ley natural es fundamental. Sin ella, piensa, se daría un relativismo moral y social en el que las primeras víctimas serían los más débiles, seres humanos y pueblos; además, la vida social y política sufriría tal deterioro que resultaría inviable. Los derechos humanos, por ejemplo, sin la aceptación de la doctrina de la ley natural, de la que la Iglesia los considera parte, no serían reconocidos o muy difícilmente.

Así presentada en su naturaleza fundamental la doctrina de la ley natural, podemos comenzar a sospechar por qué, como se vio en las elecciones pasadas, iglesias evangélicas y católicas dan tanta importancia a cierto tipo de verdades, innegociables para ellas, que pertenecen a este núcleo de lo que consideran ley natural. Entre dichas verdades, se pueden citar las siguientes: vida humana en su integralidad física, desde el nacimiento hasta la muerte natural; el ser humano, hombre y mujer, heterosexual, porque tal sería el hombre y mujer por naturaleza, es decir, creados por Dios, unión-matrimonio únicamente entre heterosexuales; familias donde los padres son heterosexuales; y oposición frontal y radical a la que llaman "ideología de género", considerada como la peor de todas las ideologías actuales. Con razón, son verdades que, en principio, pertenecen al núcleo de lo que consideran ley natural. No se pueden, pues, negociar.

Esas verdades y valores son el orden, orden querido por Dios. Lo contrario es negación de ese orden y su perversión. Por su naturaleza misma, consideran que se debe comenzar a reivindicarlas y proponerlas, desde el orden de lo natural y de lo humano, como ley natural, en el caso de la Iglesia católica; desde la revelación misma de Dios, en el caso de las iglesias evangélicas. Aunque las iglesias cuando hablan de la naturaleza humana y de la so-

6. Revelador de estas críticas es el n. ${ }^{\circ} 336$ (junio 2010) de la prestigiosa Revista

Internacional de Teología Concilium con el tema monográfico "Naturaleza humana y ley natural".

Tendencias 21: Tendencias de las religiones, de María Dolores Prieto Santana, "Nuevas perspectivas sobre la ley natural", La Revista Concilium cuestiona el concepto tradicional de la naturaleza humana, https://www.tendencias21.net/N uevas-perspectivas-sobre-la-le y-natural_a4884.html

7. Considerada «la verdadera magna charta de la doctrina social de la Iglesia sobre la ley natural» por un personaje eclesiásticamente representativo, cardenal prefecto de la Congregación para la Educación Católica, cuando vertió esta valoración. Ver Zenon Card. Grocholewski, Prefecto de la Congregación para la Educación Católica, La ley natural en la doctrina de la Iglesia. Conferencia pronunciada en la Universidad Católica Argentina "Santa María de los Buenos Aires" en el contexto de la Cátedra Internacional "Ley Natural y Persona Humana", el 5 de setiembre de 2007. http://www.uca.edu.ar/uca/comm on/grupo57/files/la_ley_nat_en _la_dtrina_de_la_igl.pdf 
ciedad, de hecho, lo hacen desde conceptos preconcebidos, a partir de lo que creen que son verdades reveladas o verdades naturales necesariamente implícitas en ellas. De ahí también las críticas que han brotado y surgen hacia la concepción institucional de la doctrina de la ley natural, incluso al interior de las mismas iglesias.

También podemos comprender por qué cada vez más en la vida diaria, social y política, este tipo de verdades y de valores son presentados y defendidos por los hombres y mujeres, como valores y derechos humanos o, de manera más light, como maneras de pensar diferentes, que deben ser respetadas. Las verdades reveladas se pueden creer o no creer, a nadie se le puede obligar a creer en ellas. Ya no estamos en tiempos en los que las creencias se podían imponer. Las verdades que supone la ley natural, por más universales que sean, tienen que ser argumentadas. Se pueden discutir y se discuten. Sin embargo, en el marco de una vida democrática moderna, los derechos humanos hay que reconocerlos y respetarlos, así como se debe respetar las maneras diferentes de pensar. El corrimiento o deslizamiento de lo que se consideran verdades religiosas a derechos humanos y sociales y a maneras de pensar tampoco es ingenuo.

¿Pero existen tales verdades y valores religiosos, o humanos, pero garantizados religiosamente, incluso de manera revelada? ¿Son tan universales e inmutables como, en una perspectiva religiosa y de ley natural, se los imagina? Socialmente existen, y como tales, hay que abordarlos social, cultural y políticamente de la manera más justa y humana posible.

¿Pero existen, epistemológicamente hablando, tales verdades y valores religiosos? Los cuestionamientos y hasta el rechazo de que son objeto, en bastantes de sus puntos, no son suficientes para negarlos. Se les ha atribuido su inadecuación al anacronismo de sus fundamentos, al método deductivo que utilizan y al universalismo abstracto en el que se ubican. Como si, al haber superado estos aspectos, las iglesias, por su dimensión religiosa y espiritual, así como por sus aportes en términos de verdades y de valores, pudieran ser todavía o son portadoras de verdades y de valores humanos propios e importantes. De hecho, así son tratadas las religiones e iglesias respecto de su competencia en lo humano, incluso por un pensamiento laico.

De nuevo nos preguntamos, ¿tal suposición tiene hoy asidero epistemológico? ¿Se puede defender y mantener? En los pasos que siguen, desde una antropología que no parte de supuestos, sino de datos (Corbí 2017, 50), y desde una epistemología crítica, siguiendo al epistemólogo en axiología Marià Corbí, trataremos de mostrar qué pretensión y reconocimiento de las religiones e iglesias, como portadoras de verdades y valores religiosos-humanos, ya no son epistemológicamente posibles.

Con cambios muy profundos y en la práctica muy difíciles de que sean asumidos por estas, religiones e iglesias pueden convertirse en fuentes de espiritualidad, pero no en portadoras de verdades y de valores de naturaleza antropológica, filosófica, epistemológica y de sentido, como se creyó en el pasado. En la sociedad y cultura que estamos construyendo, por más religioso 
y espiritual que sea el ser humano, esas verdades y valores las tiene que construir por sí mismo, laicamente, como las debe construir y las construye cualquier ser humano no creyente.

\section{El ser humano como animal viviente hablante o una naturaleza humana no-naturaleza}

La convicción o supuesto de que la religión es fuente y portadora de verdades y de valores (obviamente religiosos o estrechamente relacionados con ellos como lo hemos visto en la doctrina de la ley natural) está muy ligada a la concepción del ser humano, en términos de naturaleza humana como algo dado. Se supone que con ella naceríamos y se entiende como un compuesto de cuerpo y de espíritu, de animalidad y de racionalidad. Como está ligada a esta concepción la de la ley natural (Iglesia católica 1992). Lo expresamos de pasada más arriba; por una parte, la relación entre la concepción de Dios creador; y por otra parte, la concepción de la naturaleza humana como compuesta de cuerpo y espíritu, o de cuerpo y racionalidad, es tan estrecha que, sin esta relación, la doctrina de la ley natural, tal como el magisterio de la Iglesia católica y la teología institucional la presentan, sería insostenible. Ambas concepciones son correlativas la una a la otra.

Pues bien, resulta que, de acuerdo con la antropología actual, de naturaleza eminentemente científica, esto es, que parte de datos y según la cual el ser humano es resultado de la evolución biológica, este no puede ser concebido como una naturaleza dada. Al contrario, si algo lo caracteriza, como lo plantea el epistemólogo de la axiología Marià Corbí, es precisamente no tener una naturaleza dada (Corbí 2015b, 185-189), fijada. Si la tuviera, no sería el ser humano que es, no tendría la flexibilidad que lo caracteriza (cuando crea e innova) para adaptarse a nuevas formas de vida e incluso crearlas. Su naturaleza dada o fijada le privaría de flexibilidad y le impediría ser el ser humano que es.

El ser humano no nace con una naturaleza dada o fijada, sino con unas condiciones o capacidades básicas que le permiten procurarse la naturaleza que, en cada forma de vida, necesita. Nace, como tantas veces se dice, pero de verdad genéticamente incompleto, para poder completarse culturalmente. Nace diseñado para enfrentar los cambios. Los demás animales pasan por cambios morfológicos muy lentos, de miles e incluso millones de años, mientras la especie humana puede realizarlos y los efectúa, de manera acelerada, en tiempos muchísimo más cortos, sin necesidad de cambiar su morfología; solamente, podríamos decir que cambia de "chip" cultural.

Diseñado para enfrentar cambios, el ser humano no nace con una naturaleza, nace genéticamente incompleto, pero con unas capacidades o condiciones que le permiten procurarse la naturaleza o determinaciones que, como cualquier animal, necesita para vivir. Corbí señala cuatro: nacemos dotados 
de una fisiología, somos seres simbióticos, con la naturaleza y los demás seres humanos, somos seres sexuales, y nacemos con una competencia o capacidad lingüística (Corbí 2013a, 21 y Corbí 2015b, 231). Estos elementos no nos dotan de una naturaleza, sino de la posibilidad de construirla a partir de ellos. Son necesarios, pero no suficientes. De hecho, por sí mismos no garantizan nuestra viabilidad como animales vivientes. No nos proporcionan las formas que necesitamos para vivir, tenemos que construirlas nosotros, mediante el habla.

Nuestra mera condición fisiológica es tan insuficiente que ella sola no nos constituye en seres humanos. La condición sexual con la que nacemos no implica, en principio, nada más que la posibilidad de la reproducción de la especie. De hecho, nada nos dice sobre cómo debe ser la relación hombre y mujer; de estos, con su prole; el cuido de esta última; qué significado y valor se le puede dar a la sexualidad; cómo asumirla personal, social y culturalmente.

En cuanto a cómo concebir y a vivir nuestra condición simbiótica pasa lo mismo. Esta no va más allá de exigir un cierto grado de sociedad y de equidad, porque sin algún grado de ellas, la simbiosis misma es imposible. Sin ninguna concreción sobre las formas que sociedad y equidad humana deben asumir cuando existen en concreto. $Y$ así pasa respecto de nuestra capacidad o competencia lingüística, que solo implica cierto grado de veracidad, sin el cual ninguna lengua podría cumplir su función de comunicación, por lo demás tan necesaria; no obstante, toda forma lingüística de hacerlo queda indeterminada. Nacemos con una capacidad o competencia lingüística no con una lengua. Obviamente, cada una de estas condiciones por separado, no las cuatro en conjunto, constituyen una naturaleza como algo acabado, ni siquiera viable.

De nuestra naturaleza no-naturaleza, no podemos deducir verdades, valores ni normas de comportamiento y de organización, y, menos aún, considerar que son universales, valederas para toda forma de vida. "No hay que confundir — dice Corbí - una interpretación de la realidad, idéntica durante milenios, porque corresponde a una forma fundamental de vivir con una naturaleza humana universal" (Corbí 2015b, 288). Más aún, al no poder considerarnos naturaleza, tampoco podemos considerarnos naturaleza, fijada y acabada, nada de cuanto nos rodea: cosas, los demás seres humanos, Dios. Dios tampoco puede ser concebido en términos de naturaleza, aunque en su caso se diga que es infinita, pero siempre óntica e incluso personal. Dios concebido como un ser o naturaleza dada no es más que la proyección de nuestra naturaleza precisamente cuando la consideramos fijada y fundamentalmente acabada. Esto porque si no consideráramos nuestra naturaleza así, tampoco podríamos imaginar las demás como acabadas y fijadas. Cuando lo hacemos, es una interpretación propia de culturas preindustriales, fundamentalmente agrarias, estáticas, como veremos más adelante, que ya no son las nuestras.

Donde no hay naturaleza, no hay verdades ni valores dados, hay que construirlos como se construye lo social y como parte de este, son verdades y valores mientras sean adecuados a la forma de vida de la que son parte. Cons- 
truidos por nosotros, las verdades y los valores no son religiosos ni necesitan serlo, mucho menos universales y para siempre. Lo necesario e importante es que sean funcionales, en el sentido de lo más adecuados a la forma de vida a la que sirven. Lo contrario es concebirse naturaleza fijada dentro de naturalezas fijadas y absolutizar una realización que es temporal, que es relativa. Ninguna realización relativa, temporal, debe ser absolutizada, sacralizada. La fijación, a la larga, hace inviable al ser humano, que requiere de flexibilidad, porque es un animal diseñado para el cambio sin hacerlo morfológicamente.

El ser humano, como no es un compuesto de cuerpo y espíritu, cuerpo y razón, no nace con verdades ni valores, mucho menos religiosas o espirituales, sino que él mismo las debe construir. El ser humano no es un ser que nace espiritual para conocer a Dios, su plan sobre el ser humano y el universo, y saber cómo comportarse. Tampoco es un ser racional, versión moderna, como Corbí lo califica, de la cualidad espiritual anterior, para conocer la realidad como algo que le antecede y a la que aparentemente viene.

De acuerdo con la antropología que asumimos de Marià Corbí, el ser humano es un animal viviente hablante, en el sentido radical de los términos. No es un ser con espíritu o con razón, lo que supone realidades acabadas y transcendentes por dinámicas que lo han precedido o rodeado. Ni siquiera es un animal viviente que, además de vivir, habla. Es un animal viviente constituido como tal por el habla y mediante el habla. El habla es lo que lo constituye biológicamente como el animal viviente que es. En palabras de Corbí, "Los humanos no somos un espíritu y un cuerpo, no somos unos animales que razonan, no somos animales que hablan, nos hacemos animales viables hablando" (2013a, 50). El ser humano construye su realidad y se construye a sí mismo hablando. Y en esto no hay nada de religioso, mucho menos de divino o sobrenatural. Incluso no hay nada de natural si por natural entendemos algo ya sustancialmente acabado. Como dice Corbí, "Nada hay natural para el animal constituido por el habla, cuya naturaleza es una no-naturaleza" (2017, 44).

¿Qué significa el habla que tiene tal poder de constituir al ser humano? El habla supone conocer todo lo objetual, incluso lo que es conceptual, en términos de significado, así como la capacidad de poner ese significado en un soporte fonético que pronto se va diversificando en soportes de las más variadas formas expresivas, no solo fonéticas. De esta manera, aunque generalmente sea de forma inconsciente, cuando conocemos, tenemos un doble conocimiento de la realidad u objeto conocido; de la realidad u objeto en su significado; y de la realidad u objeto en sí misma considerada. Un doble conocimiento, con un doble acceso a la realidad, invento maravilloso de la biología, así como la articulación que muestra y constituye, y en los que no hay nada de religioso, mucho menos divino, sino pura biología de un animal viviente hablante.

Conocer la realidad, en términos de significados, es una necesidad en función de la vida, a la que Corbí llama dimensión relativa (DR), por su relación con la vida, mientras conocer la realidad en sí misma considerada, es la reali- 
dad a la que a su vez llama dimensión absoluta (DA) (Corbí 2015b, 137-153; Corbí 2017; y Corbí 2012, 171-179), es una necesidad de conocer la realidad en términos de significado (DR). Vía el conocimiento, se constata en el viviente humano, pues una dimensión absoluta (DA), pero esta es una necesidad de la dimensión relativa (DR), tal como la conocemos y necesitamos conocerla para vivir viablemente como seres humanos. Sobre la DA así descubierta, en ella, se fundó, como veremos, lo religioso en determinadas formas de vida humana, no a priori, pero como el habla, y con ella, fue una invención de la vida. No es nada religiosa, aunque en sí misma se ha considerado gratuita, infinita, absoluta (en el sentido de "suelta" o libre de toda forma y contenido), características o cualidades no religiosas, puramente humanas, podríamos decir pura y solamente biológicas, aunque parezcan religiosas y divinas.

El habla no solamente constituye al ser humano como el animal viviente que es, sino que establece correlativamente a él toda la realidad, y todo (ser humano y realidad) queda formado como realidades interdependientes. Si ante el ser humano, concebido en términos de naturaleza fijada, todo es visto como ontología -y una ontología, dualista y jerarquizada, divina (religiosa) y humana, natural y no natural-, ante el ser humano concebido como animal viviente hablante, con su doble acceso a la realidad y esta en su doble dimensión, DR y DA, todo aparece y demanda ser visto como interdependiente. Más que ontología lo que hay es interdependencia, y en todo hay DR y DA, sin necesidad de que haya algo religioso.

En nuestra naturaleza propia de hablantes, o sea, en nuestra no-naturaleza y en nuestra condición de hablantes, con un doble acceso a la realidad, no hay algo así como una naturaleza con una dimensión religiosa. Por naturaleza, el ser humano es un ser hablante, no es un ser religioso. La dimensión conocida como religiosa y valorada como tal no ha sido nada más que la DR correspondiente a una forma de vida, DR que ha sido naturalizada, universalizada $y$, al proyectarla sobre la DA, ha sido absolutizada e incluso divinizada, haciendo de la DA el Dios creador de la DR (Corbí 2015b, 287).

Tampoco hay verdades entendidas como copias conceptuales de cosas, de naturalezas acabadas ni de valores universales, mucho menos verdades y valores religiosos o espirituales. Como expresa Corbí, "los valores no son cosas del espíritu. Ni de su sustituto laico, la razón. Los valores son solo un asunto de vivientes necesitados y de sus organizaciones simbióticas" (2013a, 43). Lo mismo podemos decir de las llamadas "verdades". Entonces, las verdades y los valores no son copias conceptuales y axiológicas de la realidad, son modelaciones conceptuales y axiológicas que, como animales vivientes hablantes, hacemos de la realidad.

Finalmente, nuestra naturaleza no-naturaleza seguirá siendo tal, esto es, abierta, no acabada ni fijada, incluso cuando gracias al habla, se le haya dado la forma que requiere la respectiva forma de vida. En otras palabras, no hay ninguna forma de vida humana - por humana y socialmente que haya sido efectuada- que se pueda declarar, en principio, la superior, la mejor de todas, menos aún la única, como suele ocurrir en las religiones. En este sentido, pese al éxito de la forma construida, siempre la naturaleza humana es 
una no-naturaleza, siempre queda abierta y tiene que estar abierta, so pena de convertirse en fijación y traicionar su función, primera y fundamental, de dotar al ser humano y a las sociedades de flexibilidad. Aunque las religiones hablen de un momento de "plenitud de los tiempos", como lo hace Pablo en el caso del cristianismo (Gal 4, 4), en principio, no hay tal plenitud.

\section{La dimensión absoluta como dato, no religiosa}

¿DA constitutiva del ser humano es gratuita, plena, total y no religiosa? Así es, en efecto. La invención de la vida en el proceso evolutivo de esta, lo mismo que la DR, la DA es constitutiva del animal viviente hablante que somos los seres humanos. Sin ella, tampoco se daría la DR con el conocimiento que implica de la realidad en términos de significado. Este solo puede ocurrir, como se da, de manera cultural, sobre la dimensión infinita que significa y presenta todo objeto o realidad en sí mismos considerados.

La DR son las realidades captadas en función de la vida, mientras la DA son las realidades o, quizás mejor, la realidad en sí misma considerada, infinita e insondable. La primera es relativa, la segunda es absoluta. Ambas, en la imbricación de sí mismas, son constitutivas del animal viviente hablante que somos los seres humanos. La DA lo es en el ser que la caracteriza, absoluto, sin contenidos ni formas.

Solo sobre este trasfondo y en él es que se puede generar el conocimiento en términos de significado y de valor. La condición expresada parece demasiado radical, un enorme desperdicio en términos biológicos. Podríamos pensar que, para conocer algo en términos de significado, por tanto, parcial aunque necesario, haya que suponer la existencia de una dimensión absoluta, infinita, total; una dimensión que es la dimensión absoluta, la única que existe. Pero así es. Como tantas veces lo subraya Marià Corbí, la existencia de esta dimensión y su conocimiento es un dato (Corbí 2013a, 19, 25, 33 y Corbí 2015a, 22-23), un dato antropológico, presente en todo conocimiento y del que, por lo tanto, tenemos un conocimiento usualmente implícito, pero real, operativo. Y esto es suficiente. Si no se diera esta dimensión, la DA, con la radicalidad que la expresamos, gratuita como es, plena y total, absoluta, ningún conocimiento en términos de significado sería posible. Sin esta dimensión absoluta presente en todo objeto o realidad, constitutiva de ella, el supuesto conocimiento, en términos de significado, no sería tal, no sería el conocimiento ternario que es estímulo + significación + respuesta, conocimiento cultural, humano, sino el conocimiento binario, animal, de estímulo + respuesta, y este de naturaleza fundamentalmente genética.

Para ello, la DA tiene que ser, valga la redundancia, absoluta, sin contenidos ni formas, plena y total en sí misma, realización total, y por ello, gratuidad pura, nunca medio, paso o condición para un estado, condición o realización superior; nunca medio para otro tipo de conocimiento, verdad o valor. El lec- 
tor estará pesando que estamos hablando de un estado o condición espiritual, de realización plena. Efectivamente, solo que no religioso, porque si fuera religioso, sería un estado o condición con contenidos y formas, de verdades y valores tan limitados, aunque se proclamen infinitos y lo parezcan, que se convierten en dogmas y se comportan realmente como muros de contención y de exclusión. Las religiones son, en el fondo, DR por más que parezcan expresiones de la DA. Son DR y, como estas, propias de una forma de vida. De ahí que les cueste tanto enfrentar los retos que les supone el cambio en la forma de vida; el paso, por ejemplo, de una sociedad agraria a una industrial y, más aún, a una de conocimiento como la que estamos construyendo. Su identificación con el tipo de sociedad en el que emergieron y en el que se desarrollaron llega a ser tal, que verdades y valores de los que creen ser portadoras se vuelven dogmáticos, verdades y valores en sí, tal como están formulados, y no pueden aceptar otro tipo de concepción y de formulación. En consecuencia, la crisis de la religión que estamos experimentando.

¿Crisis de anacronismo? Mucho más. Si solo fuera crisis de conceptos y de valores anacrónicos, se solucionaría cambiando los pasados por otros más actuales. No obstante, siempre se mantiene, como esencial e irrenunciable, la religión como conjunto de verdades y de contenidos, tentación muy frecuente hoy en los medios religiosos. Es crisis en la pretensión misma de querer concebir lo inconcebible, la DA, en términos concebibles, de verdades y de valores, sin darse cuenta de que el nuevo conocimiento no tolera ya esta pretensión. No por prejuicios antirreligiosos, sino porque esta con su limitación impide, hace imposible, la libertad y la flexibilidad que el conocimiento necesita. Este problema no solo sucede en las religiones como cuerpos de creencias y de valores, sino en toda concepción limitada de la DA, por laica que sea tal concepción.

Así fue el fracaso de las ideologías en su pretensión por superar las construcciones mítico-simbólicas. El intento fracasó porque no se entendió la necesidad y función de la DA en la construcción del conocimiento y, por tanto, en el conocimiento de la realidad. La ideología siguió siendo mítica, persistió en querer explicar la DA como DR, y esta la entendió en términos de DR, pero la religión es el ejemplo más claro. Se ignora que solo "La noticia de la DA de toda realidad es la que nos dice que la DR siempre puede ser otra, si las circunstancias lo piden" (Corbí 2015b, 287), algo esencial para la misma DR. Hay que tener muy presente lo que ya es una experiencia cotidiana actual, que, en la nueva sociedad de innovación y cambio continuo que estamos construyendo, es inviable desde una antropología fija como la que suponen las religiones de creencias.

Así pues, la importancia de mantener los dos extremos, la DA como dato, pero no religiosa. No religiosa en términos de acabada y fijada, de conceptualizada y conceptualizable, de verdades y de contenidos, de referentes objetivistas y fijos. Por tanto, tampoco laica, si aun siendo laica, se la concibe también de esta manera. Solamente laica, si por tal se entiende la DA sin verdades ni contenidos. ¿Espiritual entonces? Así la llamaron nuestros antecesores hasta muy recientemente. El término ya no es apropiado por la conno- 
tación religiosa culturalmente inherente, pero sobre todo, por la antropología dualista que supone, hoy ya no de recibo, de cuerpo y espíritu (Corbí 2017, $30)^{8}$. Por ello, Marià Corbí prefiere llamarla cualidad humana profunda (CHP), término con toda seguridad no muy feliz, pero que tiene la virtud de intentar expresar, de una manera laica, una realidad laica como es la de la DA. Otro pensador catalán, Raimon Panikkar, a la espiritualidad prefería considerarla cualidad o dimensión humana sin más, no religiosa, solo humana, eso sí añadía - plenamente humana (Pannikar 1998, 11).

8. La noción de "espíritu" es estática. El espíritu no cambia; como consecuencia, la naturaleza humana tampoco. Entre el cuerpo y el espíritu, hay una jerarquía que se extiende a la antropología y a la sociedad.

Esta concepción antropológica laica de la DA no le quita nada de su carácter realizador; al contrario, es la concepción que mejor da cuenta de ella. Aunque si bien por su naturaleza misma la DA es realización plena del ser humano, no es esta propiamente hablando su función que, buscada como tal, siempre supondría interés y no sería tal realización. Su función biológica es la de dotar de flexibilidad al ser humano, flexibilidad que necesitamos para enfrentar los cambios y crearlos. No olvidemos que somos animales vivientes para el cambio y por ello y para ello hablantes; que la DA existe en función de nuestra biología. Adicionalmente, la DA es la dimensión realizadora por antonomasia del ser humano, plenamente realizadora por ser absoluta, total, no por ser religiosa o divina, revelada. Es en ella, en la realización humana que ofrece, donde las construcciones y creaciones humanas más desinteresadas y sublimes, como las científicas, éticas, filosóficas, estéticas y espirituales, encuentran sus raíces.

La DA es tan realizadora que, cuando descubrimos que es constitutiva de nuestra propia realidad antropológica, cuando descubrimos que somos "Eso" - como ya enseñaron las Upanishads-, ya no tiene sentido buscarla como un dios fuera de las cosas y de la realidad; y de hecho, quien hace ese hallazgo ya no la busca así. Es un ser plenamente realizado. De igual manera, es verdad lo contrario, y así, lo recogemos de Marià Corbí, resumiendo con esta cita bastante de lo que hemos venido exponiendo: "Cuando atribuimos una naturaleza fijada a nuestra condición de humanos, nos identificamos con nuestra dimensión relativa; entonces, proyectamos la dimensión absoluta, de la que tenemos noticia, a un nivel trascendente, existente como entidad fuera de toda dimensión relativa. Hacemos de la DA un dios creador de la DR" (Corbí 2015b, 287).

El carácter plenamente realizador, y por tanto espiritual, de la DA, concebida laicamente, lo confirma. Por ejemplo, la experiencia actual de hombres y de mujeres no creyentes, ateos, pero plenamente espirituales, como el caso de la pensadora francesa Geneviève Lafranchi en el siglo pasado (1997). La DA, como cultivo y experiencia, no es patrimonio de los hombres y las mujeres religiosamente interesados en ella, sino de todos los seres humanos, incluidos los no creyentes, interesados humanamente en ella, en su realización plena. Es más, en el futuro, los hombres y las mujeres espirituales pertenecerán, cada vez más, a esta categoría. Al ser cultivadores de la DA como es, sin contenidos ni formas, tendrán que hacerlo de una manera ateísta, aunque en su origen cultural sean religiosos. 
Pero siendo así la antropología humana, siendo concretamente la DA sin contenidos ni formas, ¿cómo la religión se hizo casi sinónima de verdades y de valores, de verdades y de valores fijos? ¿Cuándo y cómo ocurrió esto, en qué tipo de sociedades y de culturas? Este es el punto que abordaremos a continuación.

\section{La religión como proyecto axiológico colectivo (PAC) o la religión portadora de verdades y de valores}

Siendo la religión un campo de significado —como todo significado tiene sus raíces en nuestra condición de hablantes - y apuntando a lo absoluto, supone el doble acceso que tenemos a la realidad y, concretamente, cierta noticia de la DA. De otra manera, no podría apuntar hacia ella como lo hace. Por la función que cumplen ambas condiciones, Marià Corbí las considera y las llama nuestro núcleo antropológico (Corbí 2013a) porque constituye nuestra especificidad como vivientes.

A pesar de la función de ambas condiciones, no son suficientes para que la religión sea considerada fuente y portadora de verdades y de valores. La religión podría remitir, sin contenidos ni formas, directamente a la DA a la que apunta, como lo hacen, por ejemplo, el taoísmo y el budismo. Sin embargo, la religión de creencias, de verdades y de valores, tal como la conocemos, no lo hace así. Lo hace de una manera mediatizada. El absoluto al que remite es el de la DR, expresado a través del conocimiento y de su valoración, y por tanto, en términos de verdades y de valores. Para ello, se necesitan dos condiciones más, en las que la religión se ha dado: una forma de vida preindustrial -fundamentalmente estática - y un sistema de programación míticosimbólico y ritual colectivo. Las cuatro condiciones, a) nuestra condición de hablantes, b) nuestro doble acceso a la realidad, c) un sistema de vida preindustrial, d) y un sistema de programación mítico-simbólico, son consideradas por Corbí, y con razón, los factores generadores de las religiones (Corbí 2013a, 25-26).

Las formas sociales de vida fundamentalmente estáticas - como las sociedades preindustriales, e incluso en ciertos aspectos las industriales (por ello, Corbí las califica de 'pseudoestáticas') — demandan seguridad en su forma de vida y, como parte de esta seguridad, formas fijas de pensar, de valorar y de actuar. Son poco amigas de la innovación y del cambio, más bien tratan de controlarlos. Para ello, se dotan de un sistema o sistemas de programación mítico-simbólicos y rituales (Corbí 2013a, 22), también seguros, estables y permanentes. Este programa, marco o paradigma, brinda seguridad, estabilidad, permanencia e identidad a los colectivos sociales respectivos. Es su fuente de conducta, de inspiración y de motivación, que da sentido a su vivir, a su organización y a su actuar. Es una especie de creador de la realidad, porque esta se crea mediante el habla y el conocimiento. Sin esta programación, en estas sociedades estáticas como en cualquier otra, la vida humana, 
individual y social sería inviable. No obstante, la programación tiene que ser también adecuadamente estática, segura, repetida. Y cuando la religión funciona como programa y efectúa la programación, ella asume las cualidades necesarias de dicho programa. Se hace fija, con contenidos y formas, de verdades y valores.

Dicha marco se ha ejecutado, principalmente, en las sociedades agrarias, bajo un programa artesanal, de emisión-recepción, autoritario y jerárquico, que ontologiza la realidad y la cosifica, en la que los objetos y las cosas son objetos y cosas, el conocimiento-verdad, copia de la realidad, y la epistemología conforme a la cual actúa el conocimiento es una 'epistemología mítica', como la llama Corbí. ¿Por qué se entiende mítica o en qué sentido mítico? Porque tiene por real y objetivo lo que el conocimiento capta y describe, como si el conocimiento fuera copia de la realidad - adaequatio rei et intellectus, adecuación de la cosa con el entendimiento, definía Aristóteles la verdad, y con él los escolásticos-, y no fuera ante todo y sobre todo una modelación de ella.

Así pues, esa epistemología es mítica porque el conocimiento copia (adecuación o correspondencia del objeto o cosa no existe) es un supuesto. Pero un supuesto doblemente objetivo y objetivador, porque cree que la realidad ya en sí misma es objetiva, como siente que lo es también su conocimiento adecuado de esta. Es un supuesto que funciona muy bien. Objetividad, doble como decimos, que habita y puebla el concepto de verdad. Las verdades adquiridas con esta epistemología y gracias a ella, como los valores, son densas, tienen contenido y formas, son reales; y como vimos bajo el primer epígrafe de este trabajo, las que relevan de su naturaleza más profunda son universales, e incluso inmutables, verdades para siempre.

Por la existencia de los dos órdenes: natural y sobrenatural, divino y humano, y en virtud de la relación jerarquizada que presentan, lo sobrenatural y lo divino sancionan todo lo natural y humano, de manera que las verdades y los valores religiosos resultan todavía más verdades y más valores, plenamente verdades y valores en su orden, plenamente objetivos y verdaderos. Y la religión -que emerge de la noticia, la mayor parte de las veces meramente operativa pero real, de la DA, sin contenidos ni formas - se convierte en la fuente y portadora, por antonomasia, de verdades y de valores objetivos, de verdades y de valores que en ella alcanzan su máxima expresión y verdad y en cuanto son naturales y humanas su mayor sanción posible.

Esa imbricación de religión y verdad (verdad y valor) natural, humana, social no surge religiosamente sin más. No se da, por ejemplo, cuando la religión se queda en conocimiento, métodos y técnicas de espiritualidad, como ha sido el caso en corrientes del hinduismo, y en general, en el taoísmo y el budismo. Se origina cuando la religión, como ha sido el caso de los monoteísmos abrahámicos y otros, se ha convertido en la programación mítico-simbólica que demanda las sociedades estáticas, en el proyecto axiológico colectivo que necesitan y demandan para funcionar como sociedades en sus condiciones de vida preindustriales, proyecto que demanda toda sociedad de acuerdo con su forma de vida. Cuando la religión funciona como programación mítico-sim- 
bólica de una sociedad, cuando constituye su proyecto axiológico colectivo (PAC), como su proyecto aglutinador, motivador, inspirador y conductor, la religión tiene que ser cuerpo y vehículo de verdades y de valores, verdades y valores que cumplan esas funciones. Esta es la religión fuente y portadora de verdades y de valores, la religión como proyecto axiológico colectivo. Y con Corbí podríamos decir que "cada cultura preindustrial tenía su propia religión que funcionaba como un PAC" (Corbí 2015b, 280).

Como ya lo hemos expresado en otro momento, tales verdades y valores, analizados con rigor, en el fondo no son religiosas. Cuando son verdades son conocimientos de naturaleza fundamentalmente cosmológica y antropológica, propios de determinadas épocas y culturas, pero que, por su relación con un dios creador y revelador, son vistas como religiosas, y en las condiciones que hemos señalado, funcionan muy bien como tales. También, son verdades y valores religiosos, tal como la religión aparece y opera al comportarse como su proyecto axiológico: la religión, puente y vehículo hacia lo absoluto, pero a la vez, es y opera como programación mítico-simbólica de la sociedad. ¿Qué pasará cuando la religión no sea ya más ni pueda ser el proyecto axiológico colectivo de la sociedad?

\section{Cuando la religión ya no es ni puede ser proyecto axiológico colectivo}

Cuando la religión no sea ya un proyecto axiológico colectivo ni pueda serlo, entrará en una grave crisis, pues ha sido construida como tal y así ha funcionado exitosamente, como la programación mítico-simbólica fija que las sociedades que viven de hacer prácticamente lo mismo, estáticas o pseudoestáticas, han necesitado. No obstante, ahora estamos entrando en sociedades que viven de la innovación y del cambio y que requieren de un proyecto axiológico totalmente diferente.

Tal es la crisis a la que estamos asistiendo en la actualidad, una crisis axiológica ante todo y, sobre todo, de una axiología fija, contraria al cambio, pero religiosa también en la medida en que la religión ha desempeñado la función de proyecto axiológico colectivo, que no es otra que la de programación mítico-simbólica de la sociedad. Por ello, no solo la religión ha entrado en crisis, sino también la ideología, que le ha sucedido en la modernidad como fuente de axiología; y como la religión - pese a tener una base científica-, es también epistemológicamente mítica, cree ser una descripción de la realidad. De esta manera, se ha comportado en general la ciencia hasta el último tercio del siglo pasado. $Y$ al creer ser una descripción de la realidad, su descripción y función es fija, no es funcional a la innovación y al cambio como forma de vida. Se trata de una descripción laica, pero mítica como la religión; y como esta, sometida a la misma crisis. 
Es una crisis de axiología, de religión y de ideologías como fuentes de axiología, es una crisis de todos los PAC concebidos y formulados en términos mítico-simbólicos, porque todos ellos son equivalentes a fijación. De ahí también que la crisis de la axiología sea tan grave, la crisis más grave, en palabras de Corbí, de todas las que estamos sufriendo en la actualidad (Corbí 2013a, 12; $2015 a, 30$ y 2015b, 19 y 29). Sin embargo, no se resolverá volviendo a lo que la provoca, a una propuesta axiológica mítica, como la propuesta religiosa, porque bloquea la innovación y el cambio. $Y$ toda propuesta axiológica bloqueadora es incompatible con la flexibilidad y libertad que demandan la nueva axiología y conocimiento para ser creadores.

La crisis de la religión no es producto del laicismo, de una ideología laica versus una visión religiosa, de un deseo de autonomizarse de autoritarismos religiosos pasados o todavía actuales, aunque se haya manifestado cultural e históricamente. Es una necesidad de los animales vivientes hablantes que somos cuando enfrentamos formas de vida diferentes, cada vez más dinámicas, de innovación y de cambio. No es cuestión de preferencias o de gustos, de planteamientos más racionales versus planteamientos menos racionales, de modernidad versus tradición, aunque, repetimos, así se haya manifestado histórica y culturalmente hablando. Es una exigencia de viabilidad y de realización, individual y colectiva, que nos adentra en una forma de vida de innovación y de cambio, que estamos sintiendo. Instituciones que sirvieron, y exitosamente, para la programación mítico-simbólica de sociedades que demandaban fijación y permanencia son un peligro vitando en sociedades en las que hemos comenzado a vivir de la innovación y del cambio. No es una cuestión de religión o no religión, es de viabilidad o no viabilidad, de vida o muerte, en el nuevo tipo de sociedades.

Actualmente, en Occidente ya no hay PAC religiosos, la religión ya no puede aspirar a programar desde sus verdades y valores la sociedad, aunque, en lo que respecta al Islam y en países históricamente islámicos, sus logros en este sentido son mucho más exitosos. Se podría pensar que, en cuanto a los cristianismos y en Occidente, este no es el problema; sin embargo, fenómenos recientes como el que ha provocado esta reflexión muestran lo contrario.

De manera permanente, los cristianismos protestantes - sobre todo en su versión pentecostal y neopentecostal- y los católicos muestran su aspiración a moldear la cultura y la sociedad actuales de acuerdo con verdades y valores que siguen teniendo como características su naturaleza religiosa o natural y su fijación, y que, por su manera ya de presentarse, fija, ya no son de recibo. De entrada, se echa de menos su naturaleza racional y razonable. Apelan a una concepción y argumentación, revelación, naturaleza humana, visión de lo social y de lo político, que no es la común; no es la de la lengua franca utilizada en concepción, construcción y gestión de la nueva forma de vida plural y democrática. De ahí, la tensión permanente con conflictos ocasionales entre religión y cultura; religión y política; religión y derechos humanos; sexualidad, teoría de género... En el fondo, un problema epistemológico, un creer que, como religión, posee verdades, y no cualquier tipo de verda- 
des, sino las más fundamentales y decisivas, las que se vinculan con la realización individual y social humana.

La religión debe interiorizar en la forma de vida actual, forma de vida de innovación y de cambios continuos, ya no hay lugar para una epistemología mítica como PAC. La nueva epistemología es, y tiene que ser, crítica. De acuerdo con ella, la religión, todos los actores sociales, religiosos y no religiosos, tienen que interiorizar dos convicciones: que apuntando a la DA y llevando a ella, la religión no puede obtener verdades religiosas, sino solo ser camino hacia la pura experiencia de la DA; y que cuando piensa tener verdades operativas - que significan o pueden significar un aporte dentro de su propia tradición-, estas no son diferentes de las obtenidas críticamente, con esfuerzo y trabajo, por el común de los mortales. Por tanto, no hay para los creyentes situación de ventaja o de privilegio alguno. Respecto de las verdades que significan aportes 0 , como decimos, son operativas, los creyentes están en la misma situación de los no creyentes.

Tales convicciones no significan que los creyentes no pueden hacer aportes. Pueden y deben hacerlo, pero como el común de los mortales. Solo quiere decir lo que queda expresado: que el creyente por ser creyente, en las verdades o conocimientos que refieren a la dimensión relativa (DR) de la vida, no tienen conocimientos o verdades específicos, diferentes de los no creyentes. Sus tradiciones, ricas pese a todo en doctrinas, inspiración y motivación, no son las únicas ni son exclusivas de ellos, son patrimonio de toda la humanidad. Y en cuanto a la experiencia de la DA, esta es una posibilidad abierta a todos los seres humanos y una dimensión por cultivar. Es más, la DA como realidad ya está presente en todo ser humano, como lo está en todas las cosas. La sabiduría sutil que caracteriza a las religiones en tanto espiritualidad, sabiduría sin contenido ni forma, es patrimonio de todos los seres humanos.

En la sociedad de innovación y de cambio que estamos construyendo, ya no hay lugar para la religión como cuerpo de verdades y de valores, como programación de la sociedad o PAC, solo para la religión como experiencia de la DA o, como dice Corbí, como cultivo de la cualidad humana profunda (CHP), que nuestros antecesores llamaron espiritualidad. Según Corbí (2017), se entiende por $\mathrm{CH}$ la cualidad todavía condicionada por los intereses del ego; se entiende por CHP la cualidad ya no condicionada por los intereses del ego, podríamos calificarla de una cualidad humana incondicional. Sin embargo, la religión ha sido lo que ha sido, cuerpo de verdades y de valores, programación mítico-simbólica en las sociedades preindustriales; y en la sociedad de innovación y de cambio, o sociedad de conocimiento, no hay espacio para la religión. No hay verdades ni valores religiosos, que solo puedan aportar bienes a la nueva sociedad. No hay verdades ni valores religiosos de naturaleza progresista que, por ser tales, signifiquen un aporte valioso en el presente y en el futuro. Toda verdad o valor religioso es fijación, produce fijación, y por este hecho, es incompatible con la nueva sociedad. No hay un medio "religioso", entre la experiencia de la DA, sin forma ni contenidos, y las verdades causan fijación. Toda verdad o valor pretendidamente religioso es fruto de la 
fijación y causa fijación. El reto es que las religiones se conviertan en espiritualidad.

Creyentes y religiosos tienen que interiorizar las dos convicciones señaladas y actuar en consecuencia. Cambiar nuestro mundo y transformarlo no se puede hacer sin valores, sin axiología, sin construir el PAC correspondiente, en el cual debe estar, explícitamente postulado y axiológicamente formulado, el cultivo de la cualidad humana $(\mathrm{CH})$ y de la cualidad humana profunda (CHP), so pena de muy graves riesgos (Corbí 2015a, 34). Pero ya no puede ser religioso, ni siquiera en dominios como el de la sexualidad, de la educación o de la familia. El criterio tiene que ser antropológico, ético, filosófico, pero no religioso. En cuestión de verdades y de valores, la religión no tiene competencia: o es propuesta y cultivo de la espiritualidad auténtica, y por tanto, realización humana plena y total, sin forma ni contenidos; o las verdades y valores que ofrece no son tales, son verdades y valores anacrónicos; y si no lo son, sí son pertinentes, se trata de verdades y valores redundantes de otras disciplinas, travestidos como religiosos. Su pretendido valor religioso ni les ayuda ni les añade nada, más bien los perjudica.

Ese cambio de enfoque que retoma el cultivo de la CHP no quita que las religiones puedan seguir y continúen como los grandes sistemas simbólicos que son y podamos beneficiarnos de ellos si somos inteligentes y sabemos leerlos inteligentemente, como leemos los grandes poemas. Una de las obras de Marià Corbí está dedicada a esta lectura, la que lleva por título La sabiduría de nuestros antepasados para sociedades en tránsito. Principios de Epistemología Axiológica 2. No obstante, como sistemas simbólicos que son, tendrán que actualizarse, para que, como sistemas simbólicos, sigan siendo simbólicamente significativos porque los símbolos si no se actualizan, mueren. Esto es muy diferente de ser o volver a ser PAC, de ser fuente y portadores de un solo conjunto de verdades y de valores. En este sentido, la religión se ha vuelto insignificante y marginal, y con razón, como lo expresa Marià Corbí: "Las religiones, como sistemas de creencias y sumisiones, como PAC colectivos, están acabadas para la corriente central de la cultura humana. Son insignificantes, no significantes para las sociedades de conocimiento. Pueden durar centenares de años, pero ya en los márgenes de la cultura y como medio de protesta cultural, social y política" (Corbí 2015b, 83-84).

En este momento, lo ideal sería que las religiones ayudaran al cambio, leyéndose a sí mismas como sistemas simbólicos, pero es una tarea prácticamente imposible. Es un morir a sí mismas como sistemas de verdades y de valores para renacer a la DA de cuyo conocimiento emergieron y a la que simbólicamente apuntan. Para ello, verdades y valores hasta ahora religiosos hay que leerlos simbólicamente; sin embargo, esto sería materia de otro trabajo, así como el reto y la tarea de construir como disciplina una epistemología axiológica y formular los PAC que necesitamos. Marià Corbí los aborda en las obras citadas, sobre todo, en La construcción de los proyectos axiológicos colectivos. Principios de Epistemología Axiológica 1 y Protocolos para la construcción de organizaciones creativas y de innovación, Principios de Epis- 
temología Axiológica 3, con aportes también muy relevantes, fundamentales y fundadores en la materia.

\section{Bibliografía}

Corbí, Marià. 2012. Reflexiones sobre la cualidad humana. En una época de cambios. Barcelona: Verloc.

Corbí, Marià. 2013a. Construcción de los proyectos axiológicos colectivos. Principios de Epistemología Axiológica 1. Madrid: Bubok Publishing S.L.

Corbí, Marià. 2013b. La sabiduría de nuestros antepasados para sociedades en tránsito. Principios de Epistemología Axiológica 2. Madrid: Bubok Publishing S.L.

Corbí, Marià. 2015a. Protocolos para la construcción de organizaciones creativas y de innovación, Principios de Epistemología Axiológica 3. Madrid: Bubok Publishing, S.L.

Corbí, Marià. 2015b. El cultivo colectivo de la cualidad profunda en las sociedades de conocimiento globalizadas. Principios de Epistemología Axiológica 4. Madrid: Bubok Publishing, S.L.

Corbí, Marià. 2017. Las sociedades de conocimiento y la calidad de vida. Principios de Epistemología Axiológica 5. Madrid: Bubok Publishing, S. L.

Iglesia católica. 1992. Catecismo de la iglesia católica 1954-1960, http://www.vatican.va/archive/catechism_sp/index_sp.html

Lanfranchi, Geneviève. 1997. «Vivir en vacuidad». Cuadernos de las Diáspora, 7: 134-156.

Panikkar, Raimon. 1998. Entre Dieu et le cosmos. Entretiens avec Gwendoline Jarczyk. Paris: Albin Michel. 